\title{
A natureza (não) jurisdicional do sistema de resolução de litígios da OMC
}

https://doi.org/10.21814/uminho.ed.30.6

\author{
Andreia Barbosa \\ Professora Convidada equiparada a Professora Auxiliar \\ na Escola de Direito da Universidade do Minho
}

\section{Enquadramento temático}

A Organização Mundial do Comércio (OMC) integra um sistema tendente à resolução dos litígios que surjam entre os respetivos membros, essencialmente relacionados com os termos de interpretação e aplicação dos acordos comerciais multilaterais.

A relevância do aludido sistema fica a dever-se não só à amplitude significativa do seu âmbito de atuação, como também ao, assim recorrentemente qualificado, caráter vinculativo que as "decisões e recomendações" ali proferidas conhecem para os respetivos membros, em manifestação de um poder que é tido, também recorrentemente, como sendo jurisdicional e de cariz supranacional. Assim, ao sistema de resolução litígios da $\mathrm{OMC}$ e, em concreto, ao mecanismos pensados para dar cumprimento às suas determinações, tem vindo a ser atribuída uma efetividade assinalável, afetando, em particular, os sistemas tributários dos Estados signatários: no sentido da liberalização do comércio internacional, a OMC pressiona os Estados a reduzir ou a eliminar imposições que possam interferir nas trocas comerciais.

Não obstante, questiona-se se existirá sustento jurídico para a consideração do sistema de resolução de litígios da OMC como detentor de natureza jurisdicional.

\section{Criação, âmbito e propósitos do sistema de resolução de litígios}

A coordenação global da disciplina aplicável às transações internacionais de mercadorias e de serviços tem vindo a ser reputada como necessária, perante a constatação da emergência de padrões de consumo comuns, especialmente reconduzidos à prossecução do desenvolvimento sustentável, ainda que por via de um comércio livre, livre de fronteiras e de encargos (particularmente, de direitos aduaneiros). Esta coordenação normativa, apesar dos assinaláveis avanços já verificados, surge, porém, como de difícil concretização plena quando perspetivada a uma escala 
supranacional, e é a regulação do conflito que se tem vindo a assumir como um adequado e eficaz instrumento para ali voltado ${ }^{1}$.

O sistema de resolução de litígios da OMC surge, precisamente, como uma das formas de solucionar os litígios (disputes) que, no domínio do comércio internacional, emergem, evitando-se que extravasem para os planos político e militar. Tais litígios são, para estes efeitos, entendidos como divergências ou polarizações de interesses, pretensões ou perspetivas de Direito, de facto ou de orientação política, que sejam suscetíveis de ameaçar o comércio livre.

É o Memorando de Entendimento sobre as Regras e Processos que regem a Resolução de Litígios (MERL) - anexo 2 do acordo que institui a OMC - que cria o sistema de resolução de litígios, enquanto elemento fulcral de garantia da segurança e previsibilidade do sistema multilateral de comércio (artigo $3 .^{\circ}$, n. $^{\circ} 2$ ) e que estabelece as regras aplicáveis para o efeito. 0 Apêndice 1 do Memorando enumera os acordos abrangidos pelo sistema de resolução de conflitos da OMC. Aqui ficam incluídos o acordo que institui a OMC, os acordos multilaterais, não só sobre o comércio de mercadorias, mas também de serviços, propriedade intelectual, segurança fitossanitária e o próprio Memorando, e ainda os acordos comerciais plurilaterais, dentro de determinadas condições. Excluída do âmbito do sistema de resolução de litígios fica a impugnação de atos da OMC.

As regras do Memorando são sustentadas por um dos pilares do Direito Internacional contemporâneo: o princípio da resolução pacífica dos litígios, que conhece acolhimento na Carta das Nações Unidas, nos artigos $2 .^{\circ}$, n. $^{\circ} 4$, e $33 .^{\circ}$. Trata-se de um princípio que - ainda que se insista, hodiernamente, na necessidade de desenvolver mecanismos de prevenção dos conflitos internacionais, e não, tão só, na resolução dos mesmos $^{2}$ - decorre da proibição do recurso à força como prerrogativa da soberania dos Estados e como meio normal de resolução de conflitos.

O sistema de resolução de litígios da OMC, nos termos em que se encontra construído, é fruto da evolução verificada desde o General Agreement on Tariffs and Trade (GATT) de 1947, cujos artigos XXII e XXIII estabeleciam um sistema de consultas entre as partes contratantes para a apreciação de representações e para a resolução negociada ou mediada de conflitos. Tratava-se, portanto, de um mecanismo baseado, fundamentalmente, na capacidade negocial das partes, que procuravam chegar a uma decisão consensual, numa solução power-oriented. Na ausência de uma solução dentro de um prazo razoável, tinha lugar um inquérito por parte de um painel constituído para esse efeito e eram formuladas recomendações conciliatórias, podendo também ser impostas sanções. Pelo contrário, o atual modelo de resolução de litígios da OMC é tido como juridificado e processualizado, precisamente porque tais

1 Cf. CABRAL DE MONCADA, Luiz, O Estado Pós-Moderno - Para um novo paradigma de compreensão das actuais relações entre o Estado, o Direito e a Sociedade Civil, Lisboa, Quid Juris, 2018, p. 205, ISBN 9789727247950

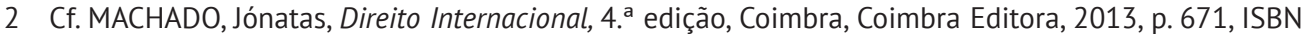
9789723221817 
litígios comerciais são encaminhados para o sistema de resolução, numa solução rule-oriented ${ }^{3}$.

Aquela abordagem power-oriented potenciava soluções baseadas em posições de poder ou de influência, enquanto que a abordagem rule-oriented implica a subordinação às normas previamente instituídas - em prol de maior previsibilidade, calculabilidade, segurança e confiança -, e afasta a politização, ainda que possa ser entendida como um excesso de legalismo e de litigância, marginalizando atores políticos, diplomatas e economistas do comércio internacional e insuflando a intervenção dos juristas ${ }^{4}$. Ainda assim, o ORL representa uma forma de preservação dos direitos e das obrigações dos Membros da OMC e contribui para a clarificação das disposições desses acordos em conformidade com as normas de interpretação do Direito Internacional Público.

A resolução de litígios comerciais representa, de resto, uma tarefa especialmente complexa, desde logo considerando que as normas da OMC não podem ser dissociadas do restante Direito Internacional, consuetudinário e convencional, de natureza geral e especial, representando apenas uma parte do todo da normação de nível global.

\section{A composição e o funcionamento do sistema de resolução de litígios}

O sistema de resolução de litígios é integrado pelo órgão de resolução de litígios (ORL), que assume como função a aplicação das normas do Memorando e das disposições de consulta e resolução de litígios previstas nos acordos abrangidos.

O ORL compreende dois graus de intervenção (referimo-nos a graus de intervenção ao invés de graus de decisão ou de jurisdição, precisamente porque se pretende aferir se o caráter jurisdicional existe, de facto, no ORL, e porque da letra do Memorando não resulta expressão diferente). É no âmbito do primeiro grau de intervenção que são designados, por regra, três elementos (panelists) ad hoc para composição de um painel, o qual deverá auxiliar o ORL no desempenho das obrigações que the são atribuídas pelo Memorando e pelos acordos abrangidos. 0 painel, composto por indivíduos altamente qualificados (artigo $8 .^{\circ}$ do Memorando), deverá concretizar uma avaliação objetiva do assunto que the seja submetido, analisando os factos e avaliando a aplicabilidade e a concordância com os acordos abrangidos e que sejam pertinentes para o caso, formulando conclusões que auxiliem o ORL na formulação de "recomendações ou decisões" (artigo 11. ${ }^{\circ}$ do Memorando). Já o segundo grau de intervenção - Appellate Body - implica a participação de pessoas de reconhecida autoridade, especialistas em Direito, em comércio internacional e nas matérias reguladas nos acordos abrangidos em geral (artigo 17. ${ }^{\circ}$ do Memorando). Ao órgão de

3 Cf. MATTHIAS OESCH, Standards of Review in WTO Dispute Resolution, Oxford, Oxford University Press, 2003, ISBN: 9780199268924, p. 4 e seguintes.

4 Cf. ROBERT HOWSE e SUSAN ESSERMAN, “The WTO on Trial”, in Foreign Affairs, jan./feb., 2004, p. 130 e seguintes. 
recurso fica vedada a apreciação do acervo fático-probatório, apenas podendo, em sede de recurso apresentado contra o relatório do painel, debruçar-se sobre questões de Direito (artigo 17. ${ }^{\circ}$, n. ${ }^{\circ}$ 6, do Memorando).

Da intervenção do ORL surgirão, então, "recomendações ou decisões", as quais se destinam a conseguir uma resolução satisfatória da questão em litígio, de acordo com os direitos e com as obrigações previstos no Memorando e nos acordos por ele abrangidos (artigo $3 .^{\circ}$, n. $^{\circ} 2$ e 4 , do Memorando).

O processo decisório do ORL é baseado no consenso e não na unanimidade, tal como acontecia no GATT de 1947, no contexto do qual as deliberações só podiam ser assim tomadas, o que incluía o voto da parte interessada, dando origem, desta forma, a bloqueios. Verificar-se-á consenso se nenhum Membro contestar formalmente a "decisão proposta”, não sendo necessário que todos votem a favor. A exigência de que exista um consenso quanto à adoção de relatórios dos painéis ou do órgão de recurso torna altamente improvável que seja bloqueada a adoção de tais relatórios, o que vem em reforço da eficácia do mecanismo de resolução de litígios no âmbito da OMC (e ainda que o normador não tenha feito uso de uma expressão que melhor fosse capaz de traduzir a suposta vinculatividade). A adoção do relatório do painel ou do órgão de recurso (que tem poderes para confirmar, alterar ou revogar as conclusões do painel) leva a que, caso o Membro em causa não diligencie no sentido de assegurar a conformidade com o acordo em análise da medida considerada incompatível com este, se procure chegar a um entendimento quanto a uma compensação satisfatória.

\section{A (não) vinculatividade das recomendações e decisões}

O relatório do Parlamento Europeu sobre o rumo da OMC trata o ORL, e em particular, o órgão de recurso, como a "joia da coroa da OMC", em virtude "do caráter vinculativo das suas decisões e do seu estatuto enquanto órgão de recurso independente e imparcial" ${ }^{n}$.

A eficácia recorrentemente reconhecida ao ORL reconduz-se, essencialmente, ao facto de se prever a possibilidade de se autorizar o Estado vencedor num determinado litígio a recorrer ao uso de sanções comerciais, suscetíveis de incluir compensações e a suspensão de concessões, quando o Estado vencido se recusar a cumprir com as recomendações e com as regras contidas nos relatórios emitidos pelo painel ou pelo órgão de recurso. E se esta é uma vantagem associada à intervenção do ORL, também serve de indicador do caráter dúbio da qualificação das recomendações e decisões como sendo juridicamente vinculativas. É que as recomendações ou regras fixadas podem vir a ser cumpridas pelo Estado vencido no litígio não por imposição do ORL, mas sim por via das medidas eventualmente adotadas pelo Estado vencedor. Aliás, na letra do próprio Memorando, no caso de um painel ou do órgão de recurso

5 Relatório do Parlamento Europeu de 22 de novembro de 2018, "Sobre a OMC: o rumo a seguir" (2018/2084(INI)), Comissão do Comércio Internacional [consultado em 2021-05-11]. Disponível na World Wide Web: <https://www.europarl.europa.eu/doceo/document/A-8-2018-0379_PT.htmll>. 
considerarem uma medida incompatível com um acordo abrangido, recomendarão ao membro em causa a conformação dessa medida com o acordo, podendo também propor formas para a execução, pelo Membro em causa, dessas recomendações (artigo $19 .^{\circ}$ do Memorando). Está-se, pois, perante recomendações, propostas.

O ORL fiscalizará a execução das recomendações ou decisões, sendo que a questão da execução das mesmas pode ser levantada no ORL por qualquer Membro, em qualquer momento após a sua adoção (artigo $21 .^{\circ}$, n. $^{\circ}$ 6, do Memorando). Daqui resulta que a fiscalização é meramente eventual. Acresce ainda que, mesmo que os painéis possam formular recomendações concretas para implementação da decisão, o Estado vencido dispõe de uma margem de manobra considerável no que concerne à escolha das medidas a adotar, contando com um prazo de trinta dias para manifestar quais são as suas intenções em matéria de cumprimento da decisão (artigo 21. ${ }^{\circ}$, n. ${ }^{\text {os }} 3$ e 6, do Memorando).

Ora, inexiste um ente que garanta a execução coerciva da decisão, estando apenas previsto um procedimento especial para a eventualidade de incumprimento e prevê-se a possibilidade de adoção, por parte do Estado lesado, de medidas de compensação e de suspensão de concessões, como forma de sanção ou de retaliação. Assim, quando uma medida adotada por um Estado é impugnada de forma bem sucedida por outro, esse Estado não tem necessariamente que a revogar, podendo, alternativamente, pagar uma compensação ou sofrer retaliações ${ }^{6}$.

A prática demonstra, é certo, que os Estados vencidos tendem a adotar as recomendações ou decisões proferidas, nalguns casos ainda antes até do termo do prazo para o efeito ${ }^{7}$. Não obstante, as medidas de compensação ou de suspensão de concessões, ainda que sejam consideradas como de ultima ratio, também já foram empregues, tendo incluído formas de retaliação cruzada, dirigidas a setores ou tratados distintos $^{8}$. Para além de ser questionável a adequação daquelas medidas para obter 0 cumprimento das decisões do ORL, serão elas suficientes para demover os Estados financeiramente mais prósperos? E no caso de serem Estados financeiramente mais prósperos os lesados/vencedores, e evitando o uso das medidas por consideração aos eventuais desequilíbrios de poder existentes, como garantir que mantêm uma atuação que não faça uso de uma ameaça nesse sentido? Como controlar ou evitar que as retaliações não produzem efeitos económicos e sociais negativos nos Estados menos prósperos? O que fazer se um Estado não contar com condições políticas internas para implementação das recomendações e decisões do ORL?

6 Cf. JUDITH BELLO, "The WTO Dispute Settlement Understanding: Less is More", in American Journal of International Law, 1996 [consultado em 2021-04-30], p. 416. Disponível na World Wide Web: <https://www.cambridge.org/core/services/aop-cambridge-core/content/view/037703CC2300A3280FC6D3028B706B29/S0002930000074637a.pdf/wto_dispute_settlement_understanding_less_is_more. pdf>.

7 Por exemplo, vide os casos: Panamá vs. Colômbia (DS366, 2007); Canadá vs. Japão (DS139, 2000); Argentina vs. Japão (DS445, 2012).

8 Vide o caso Estados Unidos vs. Brasil (DS267, 2014). 
E mesmo que a adesão às decisões exista, poderá ser justificada pelo cumprimento da máxima pacta sunt servanda e pelas influências externas, de caráter não jurisdicional, e da pressão que o Estado vencido é capaz de receber.

Não se coloca em causa a conceção do ORL como um meio de reforço e incentivador do cumprimento das disposições do acordo da OMC, tal, como de resto, é expressamente reconhecido no próprio Memorando, quando se diz que o sistema de resolução de litígios da OMC constitui um elemento de garantia da segurança e previsibilidade do sistema multilateral de comércio internacional. Um elemento, como outros que existem e que são capazes de contribuir para a segurança e certeza jurídicas no contexto do comércio internacional.

As consequências advindas do não acolhimento das recomendações ou decisões proferidas surgem, pois, por opção dos Estados vencedores, o que contribuiu para afastar das mesmas um caráter vinculativo. Este não é, porém, o entendimento sufragado pela maioria da doutrina, que tende a reconhecê-lo9 ${ }^{9}$, ainda que aconselhe especial prudência e contenção na interpretação de normas ambíguas ou imprecisas, a fim de não ser perturbado o consenso e os compromissos existentes, sendo recorrentemente sublinhada a importância da autocontenção jurídica e da necessidade de deferência para com a interpretação avançada pelos Estados, em nome do respeito pela respetiva soberania.

Por outro lado, afigura-se-nos incongruente que se reconheça vinculatividade às decisões e recomendações proferidas, quando a vinculatividade reconduzível às próprias regras que as sustentam é questionável. Em conformidade com o entendimento do Tribunal de Justiça da União Europeia, as regras do GATT/acordo OMC assentam no princípio básico de negociações mutuamente vantajosas e não no estabelecimento de normas gerais contendo obrigações jurídicas precisas, universalmente vinculativas. Também não conhecem aplicabilidade direta, na medida em que a invalidação, pelos Tribunais nacionais, de normas internas contrárias aos mesmos retiraria aos poderes legislativo e executivo a possibilidade prevista no próprio Memorando (artigo $22 .{ }^{\circ}$ ) de negociar soluções temporárias ${ }^{10}$.

\section{0 caráter (não) jurisdicional do sistema de resolução de litígios}

Mas será a ausência de uma efetiva vinculatividade das recomendações e decisões proferidas no sistema de resolução de litígios motivo bastante para se concluir no sentido de que lhe deverá ser negada a natureza jurisdicional, não se podendo falar, assim, de uma efetiva "jurisdição universal" em matéria de comércio internacional ${ }^{11}$ ?

\footnotetext{
9 Por todos, vide MACHADO, Jónatas, Direito Internacional, op. cit., p. 553, e obras ali citadas.

10 Vide, por exemplo, o acórdão proferido no caso Portugal vs. Council, processo C-149/96.

11 Cf. MAGALHÃES, Tarcísio Diniz, Governança Tributária Global: Limitações Externas ao Poder de Tributar (e de Não Tributar) na Pós-Modernidade, Belo Horizonte, Arraes Editores, 2018, ISBN: 978-8582382516, p. 167.
} 
Um Tribunal é um órgão independente, ao qual determinado(s) ordenamento(s) reconhece $(m)$ a competência para decidir e se pronunciar, como última palavra, vinculativa, acerca de questões jurídicas. Para que se possa, então, estar perante um Tribunal, é necessário que a sua finalidade primordial se reconduza à obtenção da paz jurídica, por meio da decisão de verdadeiras questões jurídicas (litígios ou aferição da conformidade legal de determinado ato com um determinado parâmetro de validade - norma jurídica); e que aos respetivos membros - juízes - devem ser reconhecidas as prerrogativas de dupla independência: objetiva (subordinação ao Direito e não a pautas políticas, por exemplo) e subjetiva (inamovibilidade e irresponsabilidade em consequência das decisões tomadas). Para além de em nenhum dos graus de decisão ser sequer empregue a expressão "judge (empregando-se antes o termo "person", o que por si só afasta a intenção de se qualificar estes elementos como juízes), do Memorando não resulta a adequada consagração de tais prerrogativas (a seleção dos membros do painel feita "tendo em vista a sua independência" - artigo $8 .^{\circ}$, n. $^{\circ} 1$, do Memorando - não coincide com a objetividade que deve ser garantida num Tribunal).

Ora, se assim é, parece ser difícil reconhecer ao sistema de resolução de litígios da OMC a qualidade de Tribunal, enquanto órgão jurisdicional. Estará, isso sim, mais próximo da conciliação, enquanto meio não jurisdicional de resolução de litígios, ao implicar a submissão das posições em confronto a uma comissão especialmente qualificada (experts), tendo em vista o esclarecimento da questão a partir dos vários pontos de vista. Trata-se esta de uma conclusão que, de resto, vai ao encontro do entendimento segundo o qual, na esfera internacional, devem ser promovidos procedimentos alternativos na resolução de litígios, centrados na adoção de formas amigáveis, ao invés de formas judiciais ou de outras tidas como agressivas, que privilegiem a resolução de conflitos por via da negociação de cedências mútuas, de acordo com os interesses dos Estados envolvidos. 